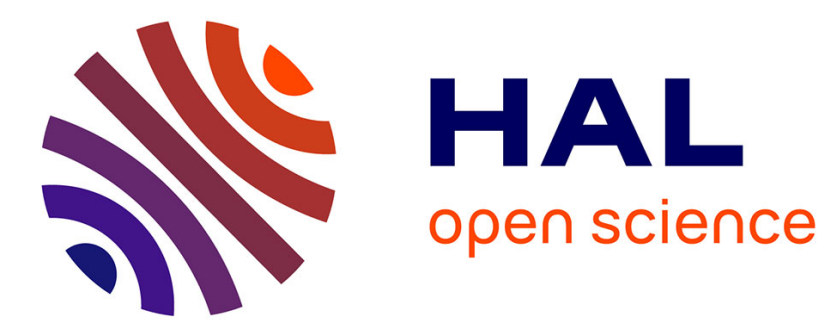

\title{
'I'd rather not take Prozac': stigma and commodification in antidepressant consumer narratives
}

\author{
Regina Smardon
}

\section{To cite this version:}

Regina Smardon. 'I'd rather not take Prozac': stigma and commodification in antidepressant consumer narratives. Health, 2008, 12 (1), pp.67-86. 10.1177/1363459307083698 . hal-00571440

\author{
HAL Id: hal-00571440 \\ https://hal.science/hal-00571440
}

Submitted on 1 Mar 2011

HAL is a multi-disciplinary open access archive for the deposit and dissemination of scientific research documents, whether they are published or not. The documents may come from teaching and research institutions in France or abroad, or from public or private research centers.
L'archive ouverte pluridisciplinaire HAL, est destinée au dépôt et à la diffusion de documents scientifiques de niveau recherche, publiés ou non, émanant des établissements d'enseignement et de recherche français ou étrangers, des laboratoires publics ou privés. 


\author{
Regina Smardon ${ }^{1}$ \\ University of Virginia USA
}

\begin{abstract}
A B S T R A C T This article explores the idea that narrative is the primary vehicle through which antidepressant consumers negotiate their sense of identity and reality. Antidepressant consumers represent a unique consumer culture because of the stigma that society attaches to mental illness. Recent media attention, including direct to consumer (DTC) advertising, appears to decrease the stigma surrounding antidepressant use while at the same time commodifying and branding them for mass consumption. Antidepressant consumers must negotiate the threat of stigma and the threat of commodification through the process of constructing narratives. Exploring the narrative process of identity negotiation reveals how the interconnected cultural processes of stigma and commodification are undergoing historical shifts. Among these shifts are the intensification of branding and an expansion of consumer culture. Implications for health promotion and further research are discussed.
\end{abstract}

KEYWORDS antidepressant branding; commodification; consumer culture; narrative; stigma

ADDRESS Regina Smardon, The Institute for Advanced Studies in Culture, Garrett Hall B068, P.O. Box 400816, Charlottesville, VA 229044816. [e-mail rS8yf@cms.mail.virginia.edu]

[A]nd I like, I have to tell you that I like taking something that's not Prozac or Zoloft; it's just this thing that nobody knows about. Umm so...

I didn't attach it to anything in particular... it's just enigmatic enough that I wouldn't... you know like if somebody looked in my medicine cabinet they wouldn't know. Not like anybody would look in my medicine cabinet.

(Celexa consumer)

Antidepressant consumers have a special relationship to cultural representations of antidepressants. Consumer cultures that form around prescription drugs may help illuminate how lay cultures form in response to 
commodification. Vuckovic and Nichter (1997: 1297) argue that, 'Through metonymic as well as metaphoric association individuals come to be defined by the medicines which they consume as well as the images associated with these commodities'. I would like to demystify this idea by exploring how people formulate antidepressant narratives within a cultural landscape of stigma and commodification.

Despite the relative absence of work exploring the meaning of medicine in consumer cultures there is a great deal to be gained from mining the rather large body of work devoted to studying illness narratives (Frank, 1995; Mattingly and Garro, 2000; Kleinman, 1988). There is also a great deal to be gained by revisiting classic sociological studies of drug use such as Howard Becker's study of marijuana use (Becker, 1963) and Alfred Lindesmith's study of opium use (Lindesmith, 1947). Despite their focus on elicit drugs, these studies highlight the sociality of the drug use experience. The meaning of medicine has been explored as part of an illness career (Conrad and Schneider, 1980; Goffman, 1959a; Karp, 1993). This work builds on Erving Goffman's insights about the presentation of self in society (1959b) and the management of stigma (1963). Research on the meaning of noncompliance has extended debate around the meaning of medication. Cohen et al. (2001: 445) point out that, '[N]on-compliance - irrational from a medical standpoint - may express, as various authors have proposed, deliberate strategies by patients to affirm their autonomy, or to reject an attributed incapacity'.

Combining the study of illness narratives, the meaning of medicine and the concept of stigma management, provides the foundation for linking the micro-sociological process of consumer meaning making in face-to-face interactions with more macro-socio-cultural patterns of consumption and production. Sidney Mintz notes in his classic study of sugar production and consumption, 'As uses change or are added on, as use both deepens and broadens, meanings also change'. (Mintz, 1985). Similarly, the relationship between the production and the consumption of antidepressants has changed over time as their uses have broadened. ${ }^{2}$ Commodification makes the unique common. As commodities, antidepressants exemplify the empirical complexity that pharmaceuticals offer the study of globalization processes. In certain respects, pharmaceuticals are not common things and thus have much to offer a theory of the social life of things (Appadurai, 1986). They are not common in the sense that prescription medicine requires the judgment of an expert to provide an individualized diagnosis and treatment plan tailored to a patient's specific needs. ${ }^{3}$ Antidepressants may also take on a singular meaning when they serve as a trigger for personal change and reinterpretation of self (Karp, 1996) or as a means of reconfiguring social relations of responsibility (Nichter and Vuckovic, 1994). Cohen et al. (2001) argue that these and other meanings of psychotropic medication are topics that deserve greater attention. Indeed, the sense that lay culture makes of 
these medications may be very different from those intended by advertisers or health professionals.

The transformation of a prescription drug from strictly a tool of medical practice to a product that may be sought or declined on the basis not only of 'lay knowledge' but, more precisely, consumer product knowledge, could have profound implications given the ways in which such knowledge is obtained, perceived and applied (Cohen et al., 2001: 453).

Antidepressants are things-in-motion that warrant methodological focus because they can serve to illuminate their human and social context (Appadurai, 1986). Antidepressants are uniquely suited to the study of commodification because of the rapid expansion of their use since the 1950s (Healy, 1997) and their status as the top-selling category of prescription drugs in the USA (NIHCM, 2002). Available estimates suggest that global sales of antidepressants and mood stabilizers were the third-ranked therapy class, up $10 \%$ in 2003 , to $\$ 19.5$ billion (IMS, 2004). Therefore, antidepressants are rapidly becoming a globalized commodity.

\section{Collecting antidepressant narratives}

The decision to take antidepressants is not an unthinking one in which people blindly follow their doctors' orders, nor do people simply follow the advice that pharmaceutical companies deliver on prime time television. In his interview-based studies of the depression experience, David Karp found that people's willingness to begin a drug treatment involves a host of complex considerations not the least of which is the ambiguity surrounding the causes of depression (Karp, 1993, 1996, 2006). I set out to discover the meaning of antidepressants in people's illness narratives, much the same way that Karp did for his latest book (Karp, 2006). In light of recent developments concerning direct to consumer (DTC) advertising, it is instructive to note the similarities and differences in Karp's first interviews, collected between 1991 and 1993 and his later interviews, collected post-2001.

Although Karp's analysis does not focus on commodification or consumer culture specifically, he reports extensively on the meaning of antidepressants, and his informants clearly possess brand awareness. My own interviews collected in 2000 echo this brand awareness.

Both Karp's work and my own are based on retrospective narratives. Many of the people in Karp's earlier study appear to have been diagnosed with depression before the introduction of Prozac in 1987. Karp's post-2001 interviews suggest a more critical orientation to medical authority than his work based on interviews collected in the early 1990s (Karp, 2006: 233). He complains that TV representations of antidepressants tend to leave the impression that they are infallible. On the other hand he also complains 
that anti-psychiatry figures, such as Peter Breggin, strike him as ideologues (Karp, 2006).

Like Karp, I had an easier time identifying women for interviews than men, therefore I interviewed 10 women and 6 men. ${ }^{4}$ I advertised for people who are currently taking or have taken antidepressants, thus I was seeking antidepressant narratives not depression narratives. Like Karp, I developed a snowball sample through acquaintances and supplemented those interviews with volunteers who responded to my newspaper advertisement. My approach to interviews was inspired by the active interview model (Holstein and Gubrium, 1995), in which my informants were free to shape the direction of the conversation. I began each interview by simply asking: When was the first time you ever heard about antidepressants? Whenever possible, I asked for clarification about the meaning of medication.

\section{'I'd rather not take Prozac'}

The antidepressant consumers I interviewed seemed to be very aware of brand names; this was particularly true of the young women I interviewed. These consumers seemed to be knowledgeable about different classes of antidepressants and they seemed to have a highly developed vocabulary for describing antidepressant mechanisms of action and linking brand names to these mechanisms. While Karp's 1990's interviewees seem to be parroting their doctor's descriptions of antidepressants (see Karp, 1996: 78-103), many of the people I interviewed referred to other sources of information; chief among these sources were fellow antidepressant consumers who possess the authority of personal experience. Karp's post2001 interviewees also seem to have a more critical edge than his previous sample, the interviewees advocating searching out information beyond a doctor's advice (Karp, 2006: 232-6).

Although my sample is hardly representative, combined with Karp's study it seems likely that antidepressant consumers were more likely to find one another in the late 1990s than the late 1980s because a) There are more of them, and/or b) Society is becoming more open to antidepressant treatment. It seems likely that the introduction of direct to consumer (DTC) advertising of prescription drugs to the US market in 1997 has encouraged the formation of consumer cultures. None of my interviewees can be said to have 'discovered' their depression as a result of the direct to consumer advertising (DTC) that emerged after 1997, most were well aware of DTC advertising and some tended to resent it very much. In particular, some who suffered from serious and/or chronic mental illness worried that advertising served to belittle their plight rather than reduce social stigma.

To my knowledge there did not exist any television advertisements for antidepressants that discussed 'suicidal ideations' during the time period 
that my narratives were collected. Instead, they tended to focus euphemistically on sadness, irritability, worrisome thoughts and loss of interest. In addition to misrepresenting mental illness, antidepressant advertising, for both professionals and the lay public, tends to overstate the effects of medicine (Goldman and Montagne, 1986; Montagne, 2001). ${ }^{6}$

In her book, No Logo (2000), Naomi Klein documents how particular brands (the swoosh, the shell and the arches) have been reframed by activists to represent corporate misdeeds. My interviews with antidepressant consumers suggest that Prozac had already fallen out of fashion by the year 2000. My conversation with a woman that I call Helena illustrates how stigma can adhere to a brand name:

author: What kind of antidepressant did they give you?

Helena: Um a serotonin reuptake inhibitor.

author: Prozac?

Helena: No, it was Celexa. Which is a European antidepressant and I had really good results. And I wasn't too keen on taking... I'd rather not take Prozac. Just because of all the stuff attached to that. So...

author: Did you think that anything bad would happen if you took Prozac? Were you afraid of it?

Helena: No, I wasn't afraid of it, I just, you know if there were another one that could be effective that didn't have this mystique about it.

Helena's desire for the newest brand name may suggest that antidepressants are associated with better technology and advanced scientific research. However, Helena views all SSRIs as relatively interchangeable drugs that work through the same mechanism. Follow-up questions revealed that she does not necessarily believe that Celexa works better than Prozac. Her motivations can only be understood by taking the stigma associated with Prozac into account. Helena was probably the most open individual I interviewed with regards to revealing her illness identity and her choice to take antidepressants. However, like all the other antidepressant consumers I talked to, she still prefers the safety of those who understand and are sympathetic. During my interview with Helena in her office, a co-worker entered the room to get a drink of water and she abruptly changed the subject. After he closed the door behind him, Helena leaned toward me to whisper:

Helena: He takes antidepressants.

author: Really?

Helena: It is very interesting how people ... I was getting a prescription filled at the drug store and there were a lot of people there and there was this guy in front of me. And she said do you have any questions about taking Celexa and he said no. But I was like, hey he's taking antidepressants, you know when you become aware of something it's like ... 
health: 12(1)

author: And you might not have known what Celexa was before you started taking it?

Helena: Right yeah right ... and I like, I have to tell you that I like taking something that's not Prozac or Zoloft; it's just like this thing that nobody knows about. Um so ...

author: What does the word make you think of?

Helena: I didn't attach it to anything in particular ... it's just enigmatic enough that I wouldn't ... you know like if somebody looked in my medicine cabinet (author: Right.) they wouldn't know. (author: mmm) Not like anyone would look in my medicine cabinet. (Helena laughs)

Prozac, it appears, has come to represent American excess and narcissism. If we listen carefully to Helena, we can hear her telling us that she wants to control information about her antidepressant use. George Ritzer argues that branding is used as a façade to hide 'nothingness'. (Ritzer, 2004). All SSRIs, from a medical point of view, are more similar than they are different. Clinical trials do not suggest that SSRIs are really any more effective than tricyclic antidepressants (Montagne, 2001). Most research and marketing efforts surrounding antidepressants appears to focus on side effects and expanding indications for use to new disorders rather than pioneering new treatments.

\section{'I know tons of people taking antidepressants'}

I would like to suggest that in the United States prior to 1997, and to a lesser extent today, becoming an antidepressant consumer was a process pregnant with stigma potential. However, as the threat of stigma recedes, a new threat emerges, the threat of commodification. Those who have spent time in mental hospitals and found themselves in the emergency room for suicide attempts are symbolically victimized when they are mistaken for the antidepressant user who is depicted in the mass media as simply irritable and dissatisfied. This gap between representations of illness and healing and actual experience tends to dilute one's self-narrative by robbing the individual of narrative resources. In a sense it creates an existential crisis by denying reality as some people know it. Indeed, Charmaz (1983) describes the dilution of self as being a great source of suffering associated with chronic illness. How can we reconcile what we know about the intense meaningfulness of stigma with the meaning gap generated by commodification?

Due to the strong social stigma surrounding mental illness, even family members may keep their antidepressant consumption secret from one another until it seems likely that another person can benefit from this information. Although most people claimed that they felt as though they 'know tons of people on antidepressants,' many found it difficult to think of more than one person that shared this information with them prior to their own use, especially before 1997. It appears that having access to a social 
network, especially a community of antidepressant consumers, decreases the stigma associated with antidepressants and that taking the drugs increases one's access to this network. Research on antidepressant consumption has not explored the role of the antidepressant consumer network in shaping experiences of stigma. While most of the people I interviewed did not believe that taking antidepressants was shameful, they were acutely aware that others might think so.

The theme of stigma in this collection of antidepressant narratives should be viewed as historical. The past several years have been a changeable time period for the cultural meaning of antidepressants. Some would argue that it seems as though it is only a matter of time before antidepressants are viewed as being completely commonplace in society. Perhaps in some communities they already are. I am not conceptualizing stigma and commodification as a zero sum game: less stigma does not necessarily equal more commodification and vice versa. There is a more fundamental narrative process that drives the dynamics of stigma and commodification.

Sometimes, people look to the media for narrative ingredients but the representations are too thin to provide a satisfying story. Mary was very limited in her social network and also in the media sources at her disposal. She describes her attempt to make sense of a representation of depression and antidepressant treatment from television. When I asked her about her social network, she spontaneously mentioned a television show that coincidentally aired while she was in the midst of deliberating about treatment options.

Author: Did you discuss your decision about taking the antidepressants with anybody besides your doctor?

Mary: Um well, I think I talked about it with Annie, with um my boyfriend, um I think I just told my mom. I don't think she really understood. I was just like, 'well, this is what they're doing'. I just sort of announced it. Um, ... well there was an Ally McBeal show and she was prescribed Prozac and the character that played the psychiatrist said happiness does not come in church, a man, love, church any of these things, she listed off a lot of different things, it comes in a pill. It was really sort of depressing. And in the end Ally flushed away the Prozac. And I was thinking oh boy tomorrow I'm supposed to be starting my Klonopin, that's when I started Klonopin which is an anti-anxiety ...

Author: Mmhmm.

Mary: And it worked to help me fall asleep, temporarily ...

Author: What did you think about the Ally McBeal show at the time?

Mary: I thought Ally needs it more than me (laughs); the character Ally needs it more than me. I think she should try it, I think also that the show generally addressed everything and like you know she's not gonna take Prozac, sounds like a great thing, but I think if they were to do it a more believable thing I think she should have tried it. 
Mary did try taking antidepressants as she suggested Ally should. She discontinued her use after ten days without consulting her doctor. She did not consult with any friends or family because, as she points out in the interview, they do not understand. She attempts to construct a narrative that frames her experiment with antidepressants as a good effort. She seems disturbed by media representations that suggest that this effort is in vain. Mary still has problems with depression and sleep, and a treatment seems to constantly elude her. Mary's story would have required narrative elements that her doctor could not supply in order to continue her medicine use. For one thing she was not convinced that waiting more than ten days was necessary to evaluate the results of the drug. She was not convinced because the narrative ingredients provided by her doctor did not allow her to construct a satisfying story to explain her experience. Perhaps a more detailed media representation might have enabled Mary to incorporate a period of suffering that included side effects into the beginning of her drug trial. Perhaps a narrative of a friend who ultimately recovered through her use of antidepressants would have provided crucial narrative elements.

When I asked Heather who she talked with about her treatment decisions she described her family as a depression support network and a clearinghouse of information about depression. She has eight siblings; five have taken antidepressants. She does not seek out people to talk to about her treatment decisions because she relies on her family and the media sources that they supply her.

We've all read like we always read all the like the novels or the new books that come out about depression or like there's a lot of memoirs out now about women who've had depression and um, you know, like that ... that one ... there's that one woman ... um ... so its funny because we've all read all of those, like my mom just sent me this book called checked or just checking? Have you heard of that one? It's good, it's written, its kind of like a memoir. It's breezily written in little passages by this woman who clearly had OCD and how it sort of ruins her marriage, but it's really funny. She tells it in this funny little ... and then there's that one woman who wrote two memoirs, one was about growing up Catholic and the other one is about like depression, I don't know her name. Maybe that's why I don't have a bigger circle or peers because I was always reading these books too so I was always like - and that was the other side of my depression network were these books and articles. (Heather)

The memoirs supply crucial narrative ingredients that clinical encounters often fail to include. For example, there is a detailed discussion of a failed relationship, a ruined marriage in one of the memoirs described by Heather. These memoirs also help Heather find humor in her own misfortune, a feature that helps her to heal. Heather is a person who has adjusted or changed her medication several times over the past several years. She has even volunteered for a drug trial study. She feels satisfied with her own antidepressant narrative and she does not seek out new people to compare her story with. In fact she described an incident when a co-worker sought 
her out for details about her experience and how she did not have any interest in this information exchange saying, 'I thought that what she kind of wanted was somebody you know to go over all the symptoms and of the things and I'm just, I don't want to do that'. If my premise is correct, the woman who sought out Heather does not have access to a support network of people with first-hand knowledge of depression or antidepressants. What this woman is after is not simply clinical knowledge but a narrative form that she can employ that makes sense of her experience.

Why does Mary discontinue her antidepressant use after only ten days while Heather is willing to pursue different brands and dosages and even cocktails to find a therapy that works for her? Part of the reason may be that Heather has access to first-hand antidepressant narratives from her family. Mary conversely does not have access to nuanced antidepressant narratives. Her attempt to squeeze meaning out of the thin narrative supplied by a television program highlights her need for cultural resources. Ultimately, she believes that her supporters 'don't understand'.

Commodification and stigma surrounding antidepressants are related but distinct phenomena. Although commodification appears to reduce stigma, there are hypothetically other ways, perhaps better ways, that pubic awareness can be created about this treatment option. The cultural circulation of antidepressants in the media has raised public awareness of treatment options while at the same time failing to provide rich and diverse illness narratives. Hypothetically, this need not be the case, the cultural circulation of antidepressants could lead to the production of rich and diverse antidepressant narratives shared within social networks and also circulated in the media.

\section{Negotiating the spoiled and commodified self through narrative}

As a bricoleur, the self-constructor is involved in something like an interpretive salvage operation, crafting selves from a vast array of available resources, making do with what he or she has to work with in the circumstances at hand, all the while constrained, but not completely controlled by the working conditions of the moment (Holstein and Gubrium, 2000: 153).

Students of consumer culture(s) have questioned the image of the consumer as a 'dupe' or a 'hero' (Slater, 1997). Contemporary debates surrounding consumer culture have begun to question the image of the consumer as a 'postmodern identity seeker' who chooses freely between lifestyles and identities (Featherstone, 1991) and instead settled on the more laborious metaphor of the craftsman (Campbell, 2005). This metaphor seems a fitting homage to the legacy of Claude Levi Strauss ([1949]1966) who encouraged us to view the cultural actor as a bricoleur, a handyman. I propose that we view the consumer as a storyteller who creates an identity narrative using existing cultural elements and synthesizes them into a new expression. 
This storytelling is a form of cultural labor. ${ }^{7}$ The bricoleur consumer is limited by the cultural meanings and forms at his/her disposal. Stigma and commodification are forces that limit the choices available to consumers and perhaps at times trigger a 'decommodifying reaction' (Campbell, 2005; Kopytoff, 1986; Miller, 1987).

Consumers must contend with a limited selection of narrative forms and a limited vocabulary of cultural elements available to tell their stories. As Holstein and Gubrium (2000) note, the storyteller is also limited by the working conditions of the moment. They must incorporate an explanation of past, present and future social occasions and relationships. The complexity of this task explains why a consumer may be willing to accept a stigmatized label into their identity narrative and why others may encourage them to do so. The social stigma and social uses of the depression label must be considered when analyzing the forms of antidepressant narratives. The influence of social interactions and social relationships on one's orientation towards antidepressants cannot be separated from the subtle effects of labeling depression as emotional deviance. Depression is a long-term mood that is generally regarded as deviant in American society. However, the social construction of depression requires a script for linking instances of emotional deviance together under a single umbrella label. The labeling of deviant moods can be very subtle and relies on innuendo, manner, un-stated implications and especially emotion (Scheff, [1666]1999; Thoits, 1985). ${ }^{8}$ Edwin Lemert points out that it is 'behavior which puts a strain on social relationships that leads to status changes' (Lemert, 1962). He encourages us to consider that the paranoid individual may in fact rightly suspect that others are avoiding them or treating them differently. Those that I interviewed experienced a range of labeling effects from overt to covert. In some cases a person was so sensitive to the idea that their behavior might be labeled as mentally ill that they anticipated the judgments of others.

Helena initially rejected the label of depression when her therapist suggests it because she had not undergone the crucial step of self-labeling her own feelings as deviant. The second time that her therapist suggested the label of depression Helena accepted it as confirmation of her own suspicion that something is wrong.

Well I guess I questioned it first of all. And second of all I was seconded by my therapist. She said yeah I think you've had a low grade depression for a while. And um and actually now that I remember, she had said that two years ago. Maybe a year prior to my going on the antidepressant. And I went to a psychiatrist and the psychiatrist said no you're not depressed. And I was like ha ha ha I'm not depressed, you're wrong and I'm just you know ... So I knew that it wasn't normal when I was questioning it and then through talking about it to her. And the resilience that I used to have wasn't there. (Helena)

Helena was not willing to label what her therapist called a 'low grade depression' anything other than 'feeling blue' until a significant period of time had passed. After a year she felt that something was definitely wrong 
because she had not 'bounced back' as she had expected. Helena imagined herself as a person who always 'bounces back', and giving up that identity was difficult. Thomas also experienced the label of depression as contrary to his sense of self. He felt that medicalizing his suffering made it meaningless and shallow.

I didn't like the word depression. I thought it was terrible. In my hyperliterary state I thought it was an awful word, you know, I preferred melancholy you know. Because that had more of a literary history too it, so I thought OK. But I was very resistant to the idea that what I had was clinical depression. So to me what I had was hypersensitivity to the side of life that ... the dark side, the void, that life was just a painful experience. That's what I had, I didn't have depression. I didn't really admit that I had depression for a few years. Even when I was in the hospital I wasn't willing to admit that I was just one of many many people that suffered from this. (Thomas)

For Thomas and for Helena, accepting the label of clinical depression meant shifting their frameworks for experiencing a sense of self. They both initially resisted this shift but gradually changed their minds about both the label of clinical depression and the efficacy of antidepressants. Why did they shift their narratives? Perhaps because over time their narrative became less and less satisfying and explained less and less of their experiences. Perhaps the threat of commodification outweighed the stigma of a spoiled identity. Thomas does not want to be just one of many homogenized people to suffer in the exact same way. He wanted to suffer in a unique and singularly meaningful way. He did not want to let go of his view of himself as sensitive and literary just as Helena did not want to give up her narrative of resiliency and the idea that she would always 'bounce back'. They found that an alternative narrative fit their experience more closely. Helena seems to be fearful of stigma, suggesting that taking antidepressants would make her weak. Thomas seems to be suggesting that antidepressants are commodifiying; they will make him just like all the other depressed people. It is not insignificant that Thomas has a history as an inpatient and has suffered from severe depression while Helena was an outpatient whose depression was self-described as 'mild'. Yet, the process of negotiating stigma and commodification does appear to follow a similar structure in which an alternative narrative is initially resisted until it becomes clear that the gap between narrative and evidence is growing and a new narrative offers decisive advantages.

\section{Discussion: What can we learn from antidepressant narratives?}

The view of prescribed medication as a rapidly changing meaningful object has been virtually absent from the study of medication consumption (Cohen et al., 2001), and medicine socialization itself is a research topic little explored by either social science or pharmacology (Vuckovic and Nichter, 1997). To be sure, studies of pharmaceutical practice have not 
to date sufficiently explored the construction of mass media consumer cultures (Cohen et al., 2001; Van der Geerst et al., 1996). Social scientists have pointed to the need to link micro-level investigations of illness identity and explanatory models with macro-level investigation of pharmaceutical use (Nichter and Vuckovic, 1994). Focusing on consumer culture highlights the fact that consumers have a special relationship with one another that is distinct from their relations with social institutions, such as the media or medical authorities. These relations constitute a response to commodifying forces and this response reconfigures the dynamics of stigma.

Widespread awareness of name brand prescription medications presents a particularly interesting case of what Kopytoff calls singularization and commodification (Kopytoff, 1986). Commodification of medicine requires homogenization of the disease or disorder associated. The commodification of mental illness involves the blurring of boundaries between discomforts of daily living and psychiatric symptomotology, suggesting that both can be remedied through mass-marketed products (Rubin, 2004). Commodification of an illness can threaten a consumer's singular experience, suggesting that their pain and suffering is common and meaningless. Somewhat paradoxically, general awareness of antidepressants as a viable treatment option in society appears to loosen the hold of social stigma surrounding their use.

Public awareness of antidepressants could be interpreted as an opening for consumers to define their own healing process and wrest control away from the domain of physicians. ${ }^{9}$ However, doctors and consumers are not the only players defining the meaning of antidepressants in society. Medical sociologists are beginning to acknowledge that the medicalization of social problems is currently being driven by biotechnology, consumers, and managed care in the United States (Conrad, 2005) and abroad (Lakoff, 2004). ${ }^{10}$ Recent scholarship has begun to explore antidepressant marketing strategies that pharmaceutical companies use in the USA (Healy, 2006) and abroad (Applbaum 2006; Lakoff, 2006). This literature does not consider the dynamics of consumer culture in this process. Indeed, what is missing from this discussion is an understanding of how the intertwined cultural processes of stigma and commodification unfold as narratives within the context of consumer cultures.

Advertisers are motivated to expand the potential market for medicine to the mildly ill. The mildly mentally ill represent a large potential market because they are not yet diagnosed and have not yet acquired a brand preference. It is not in the advertiser's interest to represent the full range of mental illness through the media. What exactly are the motivations that drive the antidepressant consumer and where do they look for cultural information about their medicine? A rational actor model would suggest that consumers are motivated to reduce costs, pursuing for example generic SSRIs (Selective Serotonin Reuptake Inhibitors) over expensive new brands. Yet, we know that such utilitarian concerns can only partially explain the complexity of antidepressant use and its current expansion. 
Among the important social processes interceding the path to the physician (Zola, 1973) is access to other antidepressant consumers.

Cultural representations do not predict the experience of stigma; they simply mediate it. In contrast to an approach that tries to connect cultural representations of illness to the experience of stigma (Link et al.,1989; Link and Phelan, 1999; Phelan and Link, 1999), some medical sociologists and anthropologists have emphasized the healing role of narrative. Although my analysis reaffirms the power of stigma in shaping the experience of mental illness, it also suggests that narrative process further shapes the experience of stigma. Recall that the stage a person occupies in forming their narrative determines their receptiveness to accepting a label, even in some cases of involuntary hospitalization. Phil Brown (1995) has described the therapeutic value of diagnosis for many patients and Arthur Frank (1995) has written about the therapeutic value of rhetorical devices that allow stories to be told through a 'wounded body'. A narrative is provided, or created, for previously unexplained events and experiences rendering the world and one's place within it more predictable. This approach suggests asking what conditions cause an individual to interpret the stigma of mental illness as outweighing the existential pain of lacking a sense of identity. Stigma spoils an identity but it does not erase one's sense of identity altogether. When does a commodified identity become a larger crisis than a spoiled one?

Ethnomethodologists have long noted the attachment that individuals have to a particular version of reality, and their violent reactions to those who breach that reality (Garfinkel, 1967) and Erving Goffman (1959b, 1963) often observed that people present a line about themselves to the public world. The need to present a coherent narrative about the self and about the world in general may partially explain the reactions or coping orientations that individuals employ in response to the threat of stigma. Secrecy may be a strategy for managing discrediting knowledge about one's mental illness or it may be a strategy to ward off the threat of commodification; maintaining a particular narrative about one's place in the world. Peggy Thoits' work on self-labeling suggests that people can be sensitive to maintaining their selfimage as well as the one they put forth for others to inspect (Thoits, 1985). Not only are people managing discrediting knowledge; they are also protecting their identity narrative from criticism and chaos. They are protecting their own image of themselves, a higher-order priority than impression management.

\section{Conclusion: Turning stigma and commodification into healing}

The analysis I have presented here suggests that avoiding stereotypes about the mentally ill will likely decrease stigma but it is not likely to prevent the process of commodification. The finer details of the illness and healing experience must be validated and circulated to combat this process. Those interested in health promotion are beginning to realize that pharmaceutical 
companies cannot be relied upon to educate the public about mental illness (Hollon, 2005). The media, significant others and health professionals provide meanings about antidepressant use that serve as tools for making stories. The antidepressant user is a storytelling craftsperson who is limited by available cultural resources including narrative forms. To the extent that the media limits representations, this serves to diminish the storyteller's options. In the case of depression, reducing the threat of stigma and the threat of commodification is a very real part of the healing process. ${ }^{11}$ When people share their various antidepressant narratives among themselves, this trend seems to broaden and deepen representations. ${ }^{12}$ Arthur Frank (2006) claims that the important ethical task of narrative analysis is to put more stories into circulation. This insight deserves more systematic research so that it can be applied effectively to health promotion policy.

Research on DTC advertising tends to focus on doctor surveys. The primary research questions driving these studies:

1. Does DTC advertising influence the doctor-patient relationship? This is usually operationalized as doctor prescribing practices.

2. Are consumers more knowledgeable as a result of DTC advertising?

3. Does DTC advertising contribute to the rising cost of health care?

Available research generally suggests that the answers to these questions are yes, yes and yes, with some minor qualifications. Nobody is asking how DTC advertising contributes to a consumer's efforts at creating an illness narrative. A true understanding of DTC advertising must include an analysis of consumer cultures.

It is possible to argue for both positive and negative outcomes associated with the global commodification of antidepressants. On the one hand, antidepressants can save lives when the market is expanded. When the first SSRIs were introduced in Japan in 1999, the suicide rates dropped dramatically (Landers, 2002). On the other hand, branding of pharmaceuticals and associated DTC advertising seems to be one of the major factors fueling the spiraling cost of healthcare in the US ultimately leaving many Americans unable to afford health insurance. ${ }^{13}$ Public awareness of psychiatric disorders and pharmaceutical treatment has burgeoned and the stigma associated has certainly decreased, allowing for the formation of communities and networks of people who share their antidepressant narratives. These antidepressant consumer cultures contribute to societal openness about psychiatric treatment. Tragically, the limited images of mental illness, healing and medicine that are circulated in the media tend to misrepresent the experiences of the mentally ill and distort the effectiveness of antidepressants.

This study is not nearly large enough to draw conclusions about the role of gender in the formation of antidepressant consumer culture, although it seems likely that this is an important feature deserving future study. The analysis I have presented must be treated as the best evidence available 
on an under-researched topic. Our understanding of how antidepressant consumer cultures evolve is necessarily limited because the opportunity for antidepressant consumers to meet outside of the influence of medical authority has only become possible as stigma recedes. Note that even internet chat groups and support groups for antidepressant consumers have tended to be sponsored by pharmaceutical companies and refereed by medical professionals. The characteristics that distinguish antidepressant consumer cultures from one another will be of particular interest to future research, and diverse research methodologies will be necessary to capture their emergence.

Certainly the influence that consumer culture, both inside and outside the USA, has on the pharmaceutical industry is a topic that deserves further attention. As antidepressants become more commonplace in not only Europe and Japan (Wehfritz and Itoi, 2001) but also in other places on the globe, we can begin to observe how media representations become incorporated locally into antidepressant narratives by consumers. Perhaps the most obvious place to begin this work is New Zealand, where DTC advertising has been legal since 1981. How do New Zealander antidepressant consumer narratives compare with those in the United States?

Future research on antidepressant consumption could also explore the notion of 'risk' in response to the recurrent media scandals and lawsuits that claim particular brand-name antidepressants can actually cause suicide and/or suicidal ideations in particular populations of patients (Elliot Chambers, 2004; Healy, 2004). Consuming antidepressant brands in this case is a form of consuming risk (Tulloch and Lupton, 2002) and can be compared to the dynamics of risk surrounding other products recalled or questioned by the FDA. Although the spectre of risk was present in the antidepressant narratives I collected, the idea that the medicine could actually cause suicide was not a major theme. Instead, consumers tended to ruminate about unknown long-term side effects and unpleasant, but certainly not lethal, short-term side effects. How do consumers who have worked hard to build their antidepressant narratives around the threat of stigma and commodification reconcile this paradoxical risk? What role do consumers play in generating these media scandals?

Antidepressant consumers are a community interested in minimizing stigma and commodification and maximizing healing through narrative. Future research on pharmaceutical consumption ought to take seriously how antidepressant consumers incorporate media representations to tell their antidepressant narratives; specifically, how they use media signals to identify what Erving Goffman (1963) called 'the wise,' in this case laypersons who are sympathetic to and/or knowledgeable about antidepressant use. This type of research will begin to suggest a culturally sophisticated understanding of the connections between consumer culture and commodification of antidepressants. 


\section{Notes}

1. An early version of this article was presented at a round table titled: Cultural Representations of Illness and Medicine at the 2003 Eastern Sociological Meetings in Philadelphia. Thoughtful feedback to early drafts of this article were provided by Chloe Silverman, Charles Bosk, Diana Crane, Randall Collins, Danielle Kane, Laura Carpenter, Vida Bajc and Peter Buonaccorsi.

2. Judith Swazey's study of the discovery and use of Chlorpromazine (Swazey, 1974 ) is a social history of the production of a pharmaceutical commodity. This book is useful for examining the relationship between the uses of early psychotropic medications and the institutional evolution of mental health care.

3. Obviously, commodification is a matter of degree. Evidenced-based medicine conceptualizes medical treatment as a standardized product, and by extension the patient becomes a consumer. Clearly, the growth of scientific management and managed care has advanced the commodification of medical care. As Kirk and Kutchins (1992) point out, the DSM itself tends to commodify illness. I am focusing for the moment on the commodification of prescribed medication itself, which I am treating as analytically distinct for the purpose of this study.

4. Antidepressant consumers are in fact largely women. This is because two out of three adults diagnosed with clinical depression are women (Maier et al., 1999; Nolen-Hoeksema, 1990). See Blum and Stracuzzi (2004) for an analysis of the gendered representations of Prozac in large-circulation periodicals. See Lovdahl et al. (1999) for a gender analysis and comparison of Scandinavian and American advertising for antidepressants to physicians. See also Nikelly (1995) for a discussion of gender, advertising and the medicalization of depression.

5. It is interesting to note that mention of suicidal thoughts as a symptom of depression was to my knowledge not included in antidepressant television advertisements until after a series of media scandals involving research and law suits suggesting that antidepressants cause suicidal ideations. At this juncture it was in the best interest of the pharmaceutical companies to establish that suicidal thoughts are a feature of the disorder rather than the medicine.

6. This is particularly true in light of Kirsch et al.'s (2002) findings regarding placebo effects in antidepressant drug trials. Somewhat paradoxically, those who suffer from depression are often depicted as tragic unsung heros who must suffer chonically and silently without the aid of medication. Thank you to an anonymous reviewer for pointing out this nuance. My main argument here is that the diversity of suffering is depicted narrowly and strategically to target a particular market.

7. Current references to the cultural actor as a bricoleur can be found in Holstein and Gubrium (2000), Urban (2001) and also are discussed at length in Erickson (2004). All of these references attempt to modify Levi-Straus' structuralism and place the bricoleur in a more emergent social context.

8. See David Karp's The Burden of Sympathy (2001) for an account of how significant others deal with mental illness.

9. Paul Starr argues in The Social Transformation of American Medicine (1982) that the American Medical Association was largely responsible for manipulating the government through media muckrakers to establish the category of medicines that we now call 'prescription drugs'. This series of 
events, according to Starr, increased the professional power of physicians and played a role in creating the expensive medical system that now exists. Thus began a complex interdependency between pharmaceutical companies that relied on the authority of physicians to sell their products and physicians that rely on the pharmaceutical industry to supply the technology that legitimates their work. See Rubin (2004) for an analysis of the marginalization of physicians in psychotropic drug advertising beginning in the 1970s and a discussion of the connection between deinstitutionalization of the mentally ill and the institutionalization of psychotropic drug advertising.

10. To be fair, Renee Fox argued in 1977 that medicalization and demedicalization are diffuse cultural phenomenon that are not entirely driven by medical institutions and professions. Consumers are undoubtedly among the forces in society that she imagined driving the process of medicalization (Fox, 1977).

11. It is not insignificant that many health professionals consider loss of interest in previous activities and a slowing down of cognitive processing to be symptoms of depression.

12. Consider the wildly popular TV show, The Sopranos. This program includes a realistic portrayal of a patient's relationship with his psychiatrist. If my hunch is correct, this program's popularity in the early twenty-first century can be explained, in part, by the cultural void that it fills. Tony Soprano's antidepressant narrative includes a complex work and family life and a complex relationship with Prozac.

13. The Centers for Medicare and Medicaid Services have projected that between 2001 and 2011 prescription drug spending will nearly triple (NIHCM, 2002).

\section{References}

Appadurai, A. (1986). The Social life of things: commodities in cultural perspective, 85-110. Cambridge: Cambridge University Press.

Applbaum, K. (2006). Educating for global mental health: The adoption of SSRIs in Japan. In A. Petryna, A. Lakoff and A. Kleinman (Eds.), Global pharmaceuticals. Duke University Press.

Becker, H. (1963). Outsiders. New York: The Free Press.

Blum, L. and Stracuzzi, N. (2004). Gender in the Prozac nation: Popular discourse and productive femininity. Gender and Society, 18(3), 269-86.

Brown, P. (1995). Naming and framing: The social construction of diagnosis and illness. Journal of Health and Social Behavior, (Extra Issue), 34-52.

Campbell, C. (2005). The craft consumer: Culture, craft and consumption in a postmodern society. Journal of Consumer Culture, 5(1), 23-42.

Charmaz, K. (1983). Loss of self: A fundamental form of suffering in the chronically ill. Sociology of Health and Illness, 5(2), 168-195.

Cohen, D., McCubbin, M., Collin, J., and Perodeau, G. (2001). Medications as social phenomena. Health: An Interdisciplinary Journal for the Study of Health, Illness and Medicine, 5(4), 441-69. London: Sage.

Conrad, P. (2005). The shifting engines of medicalization. Journal of Health and Social Behavior, 46 (March), 3-14.

Elliott, C. and Chambers, T. (2004). Prozac as a way of life. Berkeley, CA: University of California Press.

Erickson, F. (2004). Talk and social theory. Cambridge: Polity Press.

Featherstone, M. (1991). Consumer culture and postmodernism. London: Sage. 
Fox, R. (1977). The medicalization and demedicalization of American society. Daedalus, 106(1), 9-22.

Frank, A. (1995). The wounded storyteller. Chicago: University of Chicago Press.

Frank, A. (2006). Health stories as connectors and subjectifiers. Health: An Interdisciplinary Journal for the Study of Health, Illness and Medicine, 10(4), 421-40. London: Sage.

Garfinkel, H. (1967). Studies in ethnomethodology. Englewood Cliffs, NJ: Prentice Hall.

Goffman, E. (1959a). Asylums: Essays on the social situation of mental patients and other inmates. New York: Doubleday-Anchor.

Goffman, E. (1959b). The presentation of self in everyday life. New York: Doubleday-Anchor.

Goffman, E. (1963). Stigma. New York: Simon \& Schuster.

Goldman, R. and Montagne, M. (1986). Marketing mind mechanics: Decoding antidepressant drug advertisements. Social Science and Medicine, 22 (10), 1047-58.

Healy, D. (1997). The anti-depressant era. Cambridge, MA: Harvard University Press.

Healy, D. (2004). Let them eat Prozac: The unhealthy relationship between the pharmaceutical industry and Prozac. New York: NYU Press.

Healy, D. (2006). The new medical Oikumene. In A. Petryna, A, Lakoff and A. Kleinman (Eds.), Global pharmaceuticals, 61-84. Duke University Press.

Hollon, M. F. (2005) Direct-to-consumer advertising: A haphazard approach to health. Promotion. JAMA. 293 (April 27), 2030-33.

Holstein, J. and Gubrium, J. (1995). The active interview. Thousand Oaks, CA: Sage.

Holstein, J. and Gubrium, J. (2000). The self we live by: Narrative identity in a postmodern world. New York: Oxford University Press.

IMS World Review (2004). http://www.imshealth.com/

Karp, D. (1993). Taking anti-depressant medications: Resistance, trial, commitment, conversion, disenchantment. Qualitative Sociology, 16(4), 337-59.

Karp, D. (1996). Speaking of sadness: Depression, disconnection and the meaning of illness. Oxford: Oxford University Press.

Karp, D. (2001). The burden of sympathy: How families cope with mental illness. Oxford: Oxford University Press.

Karp, D. (2006). Is it me or is it my meds?: Living with antidepressants. Cambridge, MA: Harvard University Press.

Kirk, S. and Kutchins, H. (1992). The selling of the DSM: The rhetoric of science in psychiatry. NewYork: Aldine de Gruyter.

Kirsch, I., Moore, T., Scorboria, A. and Nicholls, S. (2002). The emperor's new drugs: An analysis of antidepressant medication data submitted to the U. S. Food and Drug Administration. Prevention and Treatment. 5, Article 23. Available at http://www.journals.apa.org/prevention/volume 5/pre0050023 a.html

Klein, N. (2000). No logo. New York: Picador.

Kleinman, A. (1988). The illness narratives: Suffering, healing, and the human condition. New York: Basic Books.

Kopytoff, I. (1986). The cultural biography of things: Commodification as process. In A. Appadurai (Ed.), The social life of things: Commodities in cultural perspective, 64-94. Cambridge: Cambridge University Press. 
Lakoff, A. (2004). The anxieties of globalization: Antidepressant sales and the economic crisis in Argentina. Social Studies of Science, 34(2), 247-69.

Lakoff. A. (2006). High contact: Gifts and surveillance in Argentina. In A. Petryna, A. Lakoff and A. Kleinman (Eds.), Global pharmaceuticals, 111-135. Duke University Press.

Landers, P. (2002). Drug companies push Japan to change view of depression. Wall Street Journal. October 9.

Lemert, E. (1962). Paranoia and the dynamics of exclusion. Sociometry, 25 (March), 220.

Levi -Strauss, C. (1966). The savage mind. Chicago: University of Chicago Press.

Lindesmith, A. (1947). Opiate addiction. Bloomington, IN: Indiana University Press.

Link, B., Cullen, F., Stuening, E., Shrout, P., and Dohrenwend, B. (1989). A modified labeling theory approach to mental disorders: An empirical assessment. American Sociological Review, 54(3), 400-423.

Link, B. and Phelan, J. C. (1999). Labeling and stigma. In C. Aneshensel and J. C. Phelan (Eds.), Handbook of the sociology of mental health, 481-94. New York: Kluwer Academic Press.

Lövdahl, U., Å. Riska and E. Riska. (1999).Gender display in Scandinavian and American advertising for antidepressants. Scandinavian Journal of Public Health, 27, 306-310.

Maier. W. et al. (1999). Gender differences in the prevalence of depression: A survey in primary care. Journal of Affective Disorders.

Mattingly, C. and Garro, L. (2000). Narrative and the cultural construction of illness and healing. Berkeley, CA: University of California Press

Miller, D. (1987). Material culture and mass consumption. Oxford: Blackwell.

Mintz, S. (1985). Sweetness and power: The place of sugar in modern history. New York: Penguin Books.

Montagne, M. (2001). Mass media representations as drug information for patients: The Prozac phenomenon. Substance Use and Misuse, 36(9/10), 1267-74.

NIHCM (National Institute for Health Care Management Research and Education Foundation) (2002). Prescription drug expenditures in 2001: Another year of escalating costs. March 29. http://www.nihcm.org/pharm.html

Nichter, M. and Vuckovic, N. (1994) Agenda for an anthropology of pharmaceutical practice. Social Science and Medicine, 39(9), 1285-1302.

Nikelly, A. (1995) Drug advertising and the medicalization of unipolar depression. Healthcare for Women International, 16(3), 229-42.

Nolen-Hoeksema, S. (1990). Sex differences in unipolar depression: Evidence and theory. Psychological Bulletin. 101(2), 259-82.

Phelan, J. C. and Link, B. (1999). The labeling theory of mental disorder (I): The role of social contingencies in the application of psychiatric labels. In A. Horwitz and T. Scheid (Eds.), A handbook for the study of mental health: Social contexts, theories, and system, 139-150. Cambridge: Cambridge University Press.

Ritzer, G. (2004). The globalization of nothing. Thousand Oaks, CA: Pine Forge Press.

Rubin, L. (2004). Merchandizing madness: Pills performance, and better living through chemistry. The Journal of Popular Culture, 38(2), 369-81. 
health: 12(1)

Scheff, T. (1966/1999). Being mentally ill: A sociological theory. Chicago: Aldine.

Schneider, J. and Conrad, P. (1980). In the closet with illness: Epilepsy, stigma potential and information control. Social Problems, 28(1), 32-44.

Slater, D. (1997). Consumer culture and modernity. Cambridge: Polity Press.

Starr, Paul. (1982). The Social Transformation of American Medicine. New York, NY: Basic Books.

Swazey, J. (1974). Chlorpromazine: A study in therapeutic innovation. Cambridge: MIT Press.

Thoits, P. (1985). Self-labeling processes in mental illness: The role of emotional deviance. American Journal of Sociology, 91, 221-240.

Tulloch, J. and Lupton, D. (2002). Consuming risk, consuming science: The case of GM foods. Journal of Consumer Culture, 2(3), 363-83.

Urban, G. (2001). Metaculture: How culture moves through the world. Minneapolis, MN: University of Minnesota Press.

Van der Geerst, S., Reynolds White, S. and Hardon, A. (1996). The anthropology of pharmaceuticals: A biographical approach. Annual Review of Anthropology, 25(1), 153-78.

Vuckovic, N. and Nichter, M. (1997). Changing patterns of pharmaceutical practice in the U. S. Social Science and Medicine, 44(9), 1285-302.

Wehfritz, G. and Itoi, K. (2001). Prozac pipeline. Newsweek International August 20 p. 23.

Zola, I. (1973). Pathways to the doctor. Social Science and Medicine, 7(9), 677-89.

\section{Author biography}

REGINA SMARDON is currently a postdoctoral fellow at the University of Virginia Institute for Advanced Studies in Culture. She received her Ph.D. in Sociology from the University of Pennsylvania. Her interests include the social organization of disability, the institutionalisation of special education and the meaning of science in everyday life. 